\title{
Heart rate changes during the Valsalva maneuver in patients with isolated aortic insufficiency
}

A.E. Navarro ${ }^{1}$, D.F. Dávila ${ }^{1}$, A. Torres ${ }^{2}$, G. Bellabarba ${ }^{2}$, J.H. Donis ${ }^{2}$ and J. Casado ${ }^{1}$

\author{
${ }^{1}$ Centro de Investigaciones Cardiovasculares and \\ 2Departamento de Fisiopatologia, Universidad de Los Andes, \\ Merida, Venezuela
}

\begin{abstract}
Correspondence
D.F. Dávila

Apartado Postal 590

Merida, 5101

Venezuela

Research supported in part by CDCHT-ULA (Nos. M-483-94 and M-484-94).

Received May 16, 1996 Accepted June 25, 1997 Accepted June 25,1997

Abstract

To determine the possible relationship between left ventricular dilatation and heart rate changes provoked by the Valsalva maneuver (Valsalva ratio), we studied 9 patients with isolated chronic aortic insufficiency. Left ventricular systolic function was assessed by twodimensional echocardiography and cardiac catheterization. All patients were asymptomatic (functional class I of the New York Heart Association). The left ventricular internal diameters and volumes were significantly increased in all patients. The asymptomatic patients had either normal or slightly depressed ejection fraction $(E F>0.40)$. The Valsalva ratio of these asymptomatic patients showed no significant correlation with the left ventricular volumes or with the left ventricular ejection fraction. In other words, parasympathetic heart rate control, as expressed by the Valsalva ratio, was normal in the asymptomatic patients with left ventricular dilatation and preserved left ventricular ejection fraction. Therefore, left ventricular dilatation may not be the major mechanism responsible for the abnormal parasympathetic heart rate control of patients with acquired heart disease.
\end{abstract}

\section{Introduction}

Patients with congestive heart failure have cardiac parasympathetic abnormalities and neurohormonal activation (1-3). Cardiac parasympathetic heart rate control, as assessed by the heart rate changes during the Valsalva maneuver, is impaired in these symptomatic patients (4-6). The mechanism(s) responsible for these abnormalities is (are) unknown (7-9). It has been postulated that left ventricular dilatation may be one of the responsible mechanisms (10).

In patients who have suffered a myocardial infarction (11) and in most patients with dilated and chagasic cardiomyopathy $(12,13)$, progressive ventricular dilatation takes place on a left ventricle with segmental wall motion abnormalities. Most of these patients, although still asymptomatic, have abnormal heart rate responses during the Valsalva maneuver (14-16).

Chronic aortic regurgitation also provokes a progressive dilatation of the left ventricle (17). Chronic volume overloading usually takes place in a previously healthy myocardium $(18,19)$. This well-established fact distinguishes the left ventricle of chronic aortic insufficiency from that of most other cardiac diseases (20). Therefore, aortic insufficiency 
offers a unique opportunity to study the effects of varying degrees of ventricular dilatation on the heart rate changes occurring during the Valsalva maneuver.

In the present investigation, we postulate that if cardiac parasympathetic heart rate control, as assessed by the heart rate changes during the Valsalva maneuver, is normal in asymptomatic patients with chronic aortic insufficiency, left ventricular dilatation may not be the major mechanism responsible for the cardiovascular parasympathetic abnormalities.

\section{Patients and Methods}

Nine patients with a clinical diagnosis of isolated chronic aortic regurgitation, no past medical history of rheumatic fever and no serologic evidence of syphilis were referred to our Institute because of the presence of a heart murmur. The clinical diagnosis of isolated aortic regurgitation was based on the presence of a high-pitched diastolic murmur along the left sternal border (21). This diagnosis was confirmed by cardiac catheterization and ventricular cineangiography. The severity of the aortic valve incompetence was established according to Grossman and Dexter (22). Patients with other cardiac, metabolic or systemic diseases were excluded. Eleven age-matched healthy sedentary subjects were used as normal controls.

\section{Clinical and echocardiographic protocol}

After informed consent was obtained, all patients had their clinical history taken and were submitted to a routine laboratory workup, chest X-ray and M-mode and two-dimensional echocardiographic evaluation. The size of the left cardiac chambers was determined as follows: patients were positioned in a shallow left lateral decubitus. We used a Hewlett-Packard 77020-Ac two-dimensional echocardiographic instrument to measure areas and lengths and to estimate volumes. A 2.25 or $3.25 \mathrm{MHz}$ transducer was used. The left ventricular and atrial internal diameters were measured by M-mode and two-dimensional echocardiography. A cursor was placed on the diameter of the chamber of interest in the parasternal short-axis or long-axis twodimensional display of the heart (23).

\section{Cardiac autonomic function tests}

On the same day of the echocardiographic study, the patients were taken to a quiet semidarkened room and allowed to rest for $30 \mathrm{~min}$ in the supine position. The following sequence of cardiac autonomic function tests was performed.

Valsalva maneuver. The patients and the control subjects were instructed to maintain an expiratory pressure of $40 \mathrm{mmHg}$ for $10 \mathrm{~s}$ by means of forced expiration into a mouthpiece connected to a sphygmomanometer. The EKG was recorded during the maneuver and $15 \mathrm{~s}$ thereafter. The Valsalva ratio was calculated by dividing the maximum heart rate observed during the maneuver by the minimum heart rate after the maneuver (24).

Standing up. The patients stood up after a verbal command. The maneuver was performed over a period of 2-3 $\mathrm{s}$ and the patients remained upright for $30 \mathrm{~s}$. The EKG was recorded before, during and after the maneuver. The 30/15 ratio was calculated by dividing the minimum heart rate after the 30th beat by the maximum heart rate at the 15 th beat (25).

Facial immersion. The patients were instructed to immerse their faces in a water basin at $18-20^{\circ} \mathrm{C}$, after a normal inspiration. The maneuver was performed over a period of 20-30 s, while the subjects were sitting in front of a table. The magnitude of the bradycardic response was estimated by subtracting the minimum heart rate observed from the baseline heart rate $(26,27)$.

Both the echocardiographic evaluation and the cardiac autonomic function tests 
were performed on all patients within 6 months of cardiac catheterization.

\section{Statistical analysis}

The left ventricular function parameters and the results of the cardiac autonomic function tests obtained for patients and normal controls were compared by the $t$-test for unpaired data. The left ventricular diameters and the heart rate changes induced by the cardiac autonomic function tests were correlated by standard regression and correlation analysis.

\section{Results}

\section{Clinical, cineangiographic and echocardiographic characteristics}

We studied 9 patients $(7$ men and 2 women) with isolated chronic aortic regurgitation. All patients were in functional class I (New York Heart Association, NYHA). The baseline heart rate was similar to that of the controls (Table 1).

The diagnosis of isolated chronic aortic regurgitation was confirmed by cardiac catheterization. All patients had severe aortic regurgitation (complete and dense left ventricular opacification in 1 beat with an eventual contrast density greater than that of the aorta). Left ventricular wall motion was normal in all patients. There were no segmental wall motion abnormalities upon a quantitative analysis of the left ventricular cineangiograms (21).

The echocardiographic evaluation performed on the same day of the assessment of cardiac autonomic function revealed no discrete areas of abnormal wall motion. However, there was marked left ventricular enlargement (Table 2).

The left ventricular ejection fraction was preserved and did not significantly differ from that of the normal controls (Table 1).

\section{Cardiac autonomic function tests}

Valsalva maneuver. When compared to the normal sedentary controls the Valsalva ratio was slightly lower in the asymptomatic patients with aortic insufficiency, although not significantly different (Table 2). There was no correlation between the Valsalva ratio and the left ventricular function parameters.

Standing up and facial immersion. The heart rate changes observed during standing up (30/15 ratio) and facial immersion (brady-

\begin{tabular}{lcc} 
Table 1 - Clinical and echocardiographic characteristics. & \\
Data are reported as means \pm SD. ${ }^{*} P \leq 0.01$ compared to control ( $t$-test). \\
\hline Characteristics & Controls $(\mathrm{N}=11)$ & Patients $(\mathrm{N}=9)$ \\
\hline Clinical & & \\
Male & $9(82 \%)$ & $7(78 \%)$ \\
Female & $2(18 \%)$ & $2(22 \%)$ \\
Age & $29 \pm 13$ & $28 \pm 12$ \\
Baseline heart rate & $82 \pm 12$ & $74 \pm 10$ \\
Functional class I (NYHA) & - & $9(100 \%)$ \\
Echocardiographic & & \\
Left ventricular function & $44 \pm 6.0$ & $68 \pm 6.3^{*}$ \\
Diastolic diameter (mm) & $30 \pm 7.8$ & $45 \pm 10^{*}$ \\
Systolic diameter (mm) & $0.63 \pm 0.05$ & $0.52 \pm 0.10$ \\
Ejection fraction & - & $9(100 \%)$ \\
Normal left ventricular wall motion & - & - \\
Segmental wall motion abnormalities & &
\end{tabular}

Table 2 - Cardiac autonomic function tests.

Data are reported as means \pm SD with the $95 \%$ confidence interval given below. There were no significant differences between patients and controls (ANOVA).

\begin{tabular}{lcc}
\hline Autonomic test & Controls $(\mathrm{N}=11)$ & Patients $(\mathrm{N}=9)$ \\
\hline Valsalva ratio & $1.90 \pm 0.49$ & $1.65 \pm 0.33$ \\
& $1.63 \pm 2.10$ & $1.39 \pm 1.92$ \\
& & \\
Standing up (30/15 ratio) & $1.16 \pm 0.16$ & $1.14 \pm 0.11$ \\
& $1.07 \pm 1.25$ & $1.04 \pm 1.25$ \\
Facial immersion (beats/min) & $-31 \pm 15$ & $-25 \pm 22$ \\
& $-19 \pm 43$ & $-12 \pm 38$
\end{tabular}


cardic response) were similar in both groups of subjects. There were no significant correlations between the echocardiographic parameters of left ventricular function and the heart rate changes induced by these two cardiac autonomic function tests (Table 2).

\section{Discussion}

The Valsalva maneuver is a well-known and widely accepted test of cardiac parasympathetic function. This test, which has been used in multicenter trials to evaluate autonomic function, is reliable, consistent and operator-independent (24-28). The heart rate changes provoked during the maneuver and expressed as the Valsalva ratio are mostly dependent on cardiovagal integrity (29).

The Valsalva maneuver is abnormal in most asymptomatic patients with coronary heart disease and cardiomyopathies (14-16). The patients studied in these earlier clinical investigations had a distinct and common pathologic feature, i.e., left ventricular wall motion abnormalities (30-32). Most of these patients also had mild to moderate left ventricular dilatation. On the other hand, the ischemic and cardiomyopathic patients with a normal Valsalva ratio had either normal segmental wall motion or highly localized myocardial dyskinesis (i.e., apical aneurysms). Thus, asymptomatic patients with acquired heart disease of different etiologies and with an abnormal Valsalva ratio had segmental wall motion abnormalities and ventricular dilatation (33-37).

The mechanism(s) responsible for the abnormal heart rate changes during the Valsalva maneuver is (are) still unknown $(1,4,5)$. We (36) and other investigators (10) have postulated that progressive ventricular dilatation may diminish the normal inhibitory action of cardiac vagal afferents on the brainstem vasomotor center which in turn may decrease the efferent parasympathetic traffic to the sinus node and partially explain the abnormal heart rate changes observed dur- ing the Valsalva maneuver $(38,39)$.

In the present investigation, we studied patients with pure aortic insufficiency. We chose this clinical entity because, in asymptomatic chronic aortic insufficiency, myocardial fibrosis is discrete, does not affect systolic function and is of rather late appearance $(18,20)$. Therefore, this clinical model may allow us to study the effects of left ventricular dilatation on parasympathetic heart rate control. Our results suggest that ventricular dilatation by itself does not significantly affect the Valsalva ratio in asymptomatic aortic insufficiency.

Since the two additional tests of cardiac parasympathetic function were also normal in our asymptomatic patients with ventricular dilatation and no segmental wall motion abnormalities, we are tempted to hypothesize that, in order to impair parasympathetic heart rate control, ventricular dilatation should be associated with segmental wall motion abnormalities and/or congestive heart failure (40).

Why would segmental wall motion abnormalities of different etiologies impair parasympathetic heart rate control? Recent experimental (41-43) and clinical investigations indicate that segmental myocardial abnormalities are very likely to be related to parasympathetic heart rate control $(44,45)$. In these clinical studies ischemic patients with segmental wall motion abnormalities and impaired parasympathetic heart rate control were subjected to coronary angioplasty. Normalization of left ventricular wall motion by augmented coronary blood flow was followed by an improvement in parasympathetic heart rate control. The authors concluded that alterations in cardiac geometry, secondary to the presence of a noncontracting myocardial segment, may increase the discharge of sympathetic afferent fibers by mechanical distortion of their sensory endings. Similarly, an ischemic or necrotic myocardial segment may reduce the number of inhibitory cardiac vagal afferent fibers. Both 
mechanisms may interfere with the tonic activity of the parasympathetic fibers directed to the sinus node $(46,47)$.

In summary, our results indicate that, in asymptomatic patients with left ventricular dilatation and no segmental wall motion abnormalities, parasympathetic heart rate con- trol as indicated by the Valsalva maneuver is not impaired.

\section{Acknowledgment}

\author{
We are indebted to Miss Irlanda Márquez \\ for valuable secretarial assistance.
}

\section{References}

1. Eckberg DL, Drabinsky M \& Braunwald E (1971). Defective cardiac parasympathetic control in patients with heart failure. New England Journal of Medicine, 285: 877883.

2. Mancia G (1990). Neurohormonal activation in congestive heart failure. American Heart Journal, 120: 1532-1537.

3. The SOLVD Investigators (1994). Relation of neurohormonal activation to clinical variables and degree of left ventricular dysfunction. Journal of the American College of Cardiology, 23: 1410-1420.

4. Nishimura RA \& Tajik AJ (1986). The Valsalva maneuver and response revisited. Mayo Clinic Proceedings, 61: 211-217.

5. Eckberg DL (1980). Parasympathetic cardiovascular control in human disease: a critical review of methods and results. American Journal of Physiology, 239: H581-H593.

6. Levin AB (1986). A simple test of cardiac function based upon the heart rate changes induced by the Valsalva maneuver. American Journal of Cardiology, 18: 90-99.

7. Tsay L \& Chen JH (1990). Abnormal hemodynamic response to Valsalva maneuver in patients with atrial septal defect evaluated by Doppler echocardiography. Chest, 98: 1175-1178.

8. Bernardi L, Saviolo R \& Spodick DH (1989). Do hemodynamic responses to the Valsalva maneuver reflect myocardial dysfunction? Chest, 95: 986-991.

9. Zema MJ (1990). Heart failure and the Valsalva maneuver. Chest, 97: 772-773.

10. Floras JS (1993). Clinical aspects of sympathetic activation and parasympathetic withdrawal in heart failure. Journal of the American College of Cardiology, 22 (Suppl A): $72 \mathrm{~A}-84 \mathrm{~A}$.

11. Gaudron P, Eilles G, Kugler I \& Ertl G (1993). Progressive left ventricular dysfunction and remodeling after myocardial infarction. Potential mechanisms and early predictors. Circulation, 87: 755-763.
12. Bestetti RB, Dalbo CMR, Freitas OC, Teno LAC, Castilho OT \& Oliveira JSM (1994). Non-invasive predictors of mortality for patients with Chagas' disease: a multivariate stepwise logistic regression study. Cardiology, 84: 261-267.

13. Wallis D, O'Connell JB, Hemkin RE, Constanzo-Morin MR \& Scanlon PJ (1984). Segmental wall motion abnormalities in dilated cardiomyopathy: a common finding and good prognostic sign. Journal of the American College of Cardiology, 4: 674-679.

14. Junqueira LF (1990). Ambulatory assessment of cardiac autonomic function in Chagas' heart disease of patients based on indexes of $R-R$ interval variation in the Valsalva maneuver. Brazilian Journal of Medical and Biological Research, 23: 1091-1098.

15. Marin-Neto JA, Maciel BC, Gallo Jr L, Junqueira Jr LF \& Amorin DS (1986). Effect of parasympathetic impairment on the hemodynamic response to handgrip in Chagas' disease. British Heart Journal, 55: 204-210.

16. Fuenmayor AJ, Dávila DF, Rodríguez $L$, Donis JH, Torres A, Fuenmayor AM \& Navas M (1987). The Valsalva maneuver in chagasic patients with left ventricular segmental wall motion abnormalities and normal ejection fraction. Arquivos Brasileiros de Cardiologia, 49: 221-224.

17. Bonow RO, Lakatos E, Maron BJ \& Epstein SE (1991). Serial long term assessment of the natural history of asymptomatic patients with chronic aortic regurgitation and normal left ventricular myocardium. Circulation, 84: 1625-1635.

18. Krayenbuenhl HP, Hess OM, Monrad S, Schneider J, Mall G \& Turina M (1989). Left ventricular myocardial structure in aortic valve disease before, intermediate and late after aortic valve replacement. Circulation, 79: 744-755.
19. Villari B, Campbell SE, Hess OM, Mall G, Vassalli G \& Weber KT (1993). Influence of collagen network on left ventricular systolic function in aortic valve disease. Journal of the American College of Cardiology, 22: 1477-1484.

20. Buja LM (1985). The heart. In: Robbins SL \& Kumar V (Editors), Human Pathology. McGraw Hill, New York, 317-354.

21. Braunwald E (1980). Valvular heart disease. In: Braunwald E (Editor), Heart Disease. A Textbook of Cardiovascular Medicine. WB Saunders, Philadelphia.

22. Grossman W \& Dexter L (1980). Profile in valvular heart disease. In: Grossman W (Editor), Cardiac Catheterization and Angiography. Lea \& Febiger, Philadelphia.

23. Schnittger I, Gordon EP, Fitzgerald PJ \& Popp RI (1983). Standardized intracardiac measurements of two-dimensional echocardiography. Journal of the American College of Cardiology, 2: 934-938.

24. Schumer M, Miller-Crain G \& Pfeiter MA (1988). The study group. Diabetic autonomic neuropathy - Part II: Coefficient of variation of RR-variation and Valsalva maneuver tests. American Journal of Medicine, 85: 144-146.

25. Ewing DJ, Campbell IW, Murray A, Neilson JM \& Clarke M (1978). Immediate heart-rate response to standing: a simple test of autonomic neuropathy in diabetes. British Medical Journal, I: 145147.

26. Blix AS (1988). Cardiovascular responses to diving. Acta Physiologica Scandinavica, 133 (Suppl 571): 61.

27. O'Brein $I A D, O^{\prime}$ Hare $P$ \& Corrall RJM (1986). Heart rate variability in healthy subjects: effect of age and the derivation of normal ranges for tests of autonomic function. British Heart Journal, 55: 348354 
28. Moriarty KT, Ryder REJ \& Hardisty CA (1994). Cardiovascular autonomic function tests - are three Valsalvas' and six deep breaths necessary or will singles do? Journal of Neurology, Neurosurgery and Psychiatry, 54: 938-939.

29. Sandroni $P$, Benarroch EE \& Low PA (1991). Pharmacological dissections of components of the Valsalva maneuver in adrenergic failure. Journal of Applied Physiology, 71: 1563-1567.

30. Ideker RE, Behar VS, Wagner GS, Starr JW, Starmer CF, Lee KL \& Hackel DB (1978). Evaluation of asynergy as an indicator of myocardial fibrosis. Circulation, 57: 715-725

31. Zema MJ (1985). Prognosis after myocardial infarction: prediction in ambulatory patients by use of the Valsalva maneuver. Angiology, 34: 94-104.

32. Parisi AF, Moylliham PF, Folland ED \& Feldman CL (1981). Quantitative detection of regional left ventricular contraction abnormalities by two-dimensional echocardiography. II. Accuracy in coronary artery disease. Circulation, 63: 761-767.

33. Dávila DF, Donis JH \& Rossell R (1989). Cardiac parasympathetic abnormalities. Cause or consequence of Chagas' heart disease? Parasitology Today, 5: 327-329.

34. Dávila DF, Donis JH, Navas M, Fuenmayor AJ, Torres A \& Gottberg CF (1988). Heart rate responses to atropine and left ventricular function in Chagas' heart disease. International Journal of Cardiology, 21: 143-152.

35. Dávila DF, Donis JH \& Torres A (1992), Chagas' heart disease and neuropathy. American Heart Journal, 124: 1665-1666.
36. Dávila DF, Donis JH, Torres A, Gottberg CF \& Rossell O (1991). Cardiac parasympathetic innervation in Chagas' heart disease. Medical Hypothesis, 35: 80-84.

37. Fuenmayor AJ, Rodríguez L, Torres $A$, Donis JH, Navas M, Fuenmayor AM \& Dávila DF (1988). Valsalva maneuver: a test of the functional state of cardiac innervation in chagasic myocarditis. International Journal of Cardiology, 18: 351356.

38. Porter TR, Eckberg DL \& Fritsch JM (1990). Autonomic pathophysiology in heart failure: sympathetic-cholinergic interrelations. Journal of Clinical Investigation, 85: 1362-1369.

39. Sopher SM, Smith ML, Eckberg DL, Tritsch JM \& Dibner-Dunlap ME (1990). Autonomic pathophysiology in heart failure: carotid baroreceptor-cardiac reflexes. American Journal of Physiology, 259: H689-H696.

40. Binkley PF, Nunziata E, Haas GJ, Nelson SD \& Cody RJ (1991). Parasympathetic withdrawal is an integral component of autonomic imbalance in congestive heart failure: demonstration in human subjects and verification in a paced canine model of ventricular failure. Journal of the American College of Cardiology, 18: 464-472.

41. Barber MJ, Mueller TM, Davies BG, Gill RM \& Zipes DP (1985). Interruption of sympathetic and vagal-mediated afferent responses by transmural myocardial infarction. Circulation, 71: 623-631.
42. Minisi AJ \& Thames MD (1992). Distribution of left ventricular sympathetic afferents demonstrated by reflex responses to transmural myocardial ischemia and to intracoronary and epicardial bradykinin. Circulation, 87: 240-246.

43. Abboud FM, Thames MD \& Mark AL (1981). Role of cardiac afferent nerves in regulation of circulation during coronary occlusion and heart failure. In: Abboud FM, Fozzard HA, Gilmore JP \& Reis DJ (Editors), Disturbances in Neurogenic Control of the Circulation. American Physiological Society, Bethesda, MD, 317-340.

44. Bonaduce D, Petretta M, Piscione F, Indolfi C, Migaux ML, Bianchi V, Esposito N, Marciano F \& Chiarello M (1994). Influence of reversible segmental left ventricular dysfunction on heart period variability. Journal of the American College of Cardiology, 24: 399-405.

45. Airaksinen KEJ, Ylitalo KV, Peuhkurinen KJ, Ikakeimo MJ \& Huikuri HV (1995). Heart rate variability during repeated arterial occlusion in coronary angioplasty. American Journal of Cardiology, 75: 877881.

46. Zipes DP (1990). Influence of myocardial ischemia on autonomic innervation of the heart. Circulation, 82: 1095-1105.

47. Tseng $C D$, Wang $T L$, Lin JL, Hsu KL, Chiang FT, Lien WP \& Tseng YZ (1996). The mechanism of sympathovagal imbalance in patients with myocardial ischemia. Japanese Heart Journal, 31: 43-58. 